

\title{
Braços erguidos e a fabricação do gesto: a imagem como dispositivo disciplinar no interior do MST
}

\author{
Arms raised and the making of the gesture: \\ the use of images as a disciplinary mechanism in the MST
}

Anna Maria Dias Vreeswijk*

\begin{abstract}
Resumo: Este artigo analisa a fabricação de um gesto característico dos sem-terra ligados ao Movimento dos Trabalhadores Rurais Sem Terra (MST): o braço erguido (seja com as mãos cerradas, seja segurando um facão, um machado ou uma foice). Investiga como a direção do MST utilizou um conjunto de imagens publicadas no Jornal dos Trabalhadores Rurais Sem Terra, vinculado ao Movimento, para instituir este gesto entre os sem-terra. Para isso, esta pesquisa utiliza o conceito de disciplina de acordo com Michel Foucault (1987), em seu livro Vigiar e Punir, no qual o autor aborda a disciplina como método de controle de determinado grupo de indivíduos.
\end{abstract}

Palavras-chave: MST - Movimento dos Trabalhadores Rurais Sem Terra; discurso imagético; disciplina.

\begin{abstract}
This article examines the making of a characteristic gesture of the landless people linked to the Movement of Landless Workers (MST): a raised arm (either with a fist, or holding a machete, an ax or a sickle). It investigates how the MST has used a set of pictures published in the Official Journal of the Landless Rural Workers, owned by the Movement, in order to establish this gesture among the landless people. On that account, this research uses the concept of discipline according to Michel Foucault in his book Discipline and Punish, in which the author discusses the discipline as a method of control of a particular group of individuals.
\end{abstract}

Key-words: MST - Movement of Landless Rural Workers; visual speech; discipline.

\footnotetext{
*Graduada em História pela Universidade Federal de Goiás. Mestre em História pela Universidade Federal de Goiás. Doutoranda em História pela Universidade de Brasília. E-mail: annamdv@hotmail.com.
} 


\section{Introdução}

No Brasil, durante a ditadura militar, houve um acentuado processo de concentração fundiária, com a constituição de latifúndios agropecuários, dentro de um projeto político-econômico de modernização do campo. Os sem-terra são a parcela dos trabalhadores rurais que, expropriados ou submetidos a um processo de empobrecimento de suas condições sociais, adotou a estratégia da mobilização social na tentativa de conquistar a terra. (CAUME, 2006). Os sem-terra fundaram, em 1984, na cidade de Cascavel (PR), o Movimento dos Trabalhadores Rurais Sem Terra, o MST, posicionando-se como portadores de críticas ao modelo de produção agrícola vigente.

No interior do MST, à medida que o Movimento incorporava um determinado modelo de organização, foi instaurada uma ordem que passou a normatizar os sem-terra, através de um dispositivo de disciplinarização. Em Vigiar e Punir (1987), Michel Foucault compreende a disciplina como um método de controle dos membros de determinado grupo. A disciplina se dá pelo controle do corpo, pela distribuição dos indivíduos em determinados lugares e funções e a divisão do tempo e das atividades visando maior obediência e produtividade de cada um. Desse modo, o poder disciplinar controla para tornar cada vez mais potente e se apropriar melhor das forças que, ligadas e multiplicadas, podem ser utilizadas como um todo.

O Jornal dos Trabalhadores Rurais Sem Terra é uma importante fonte para o estudo de tal processo disciplinar. O Jornal do MST é produzido ininterruptamente desde 1981, sendo mais antigo, portanto, que o próprio Movimento, fundado oficialmente no Encontro Nacional de Sem-Terras, em Cascavel (PR). De acordo com a memória do MST (STÉDILE; FERNANDES, 1999, p.26), o Jornal teve seu início como um boletim de solidariedade às cerca de 500 famílias de agricultores acampadas na zona rural do município de Ronda Alta (RS). 
A luta desses colonos que viviam no Acampamento da Encruzilhada Natalino, dentre os vários focos de conflitos agrários em diversas regiões do Brasil no início da década de 80 , foi a que passou a ser considerada como o marco histórico do início do MST. Assim, não é por acaso que o pequeno boletim publicado em apoio à luta desses colonos seria, anos depois, considerado o marco histórico da fundação do atual Jornal dos Trabalhadores Rurais Sem Terra.

Desde a fundação do MST e a apropriação do Jornal pela direção do Movimento, grande parte dos discursos, tanto escritos quanto imagéticos, publicados no Jornal e difundidos através dele, teve o objetivo não apenas de produzir informação, mas de instruir os semterra, enquadrando-os nas mais diversas diretrizes do MST. Assim, todo um conjunto de enunciados a respeito dos sem-terra presente nesta publicação pode ser estudado como elemento discursivo do dispositivo disciplinar. Neste trabalho, é analisada uma série de imagens publicadas que instituiu determinada visibilidade dos sem-terra e modelou a conduta dos indivíduos. São imagens que focalizam semterra erguendo seus braços, num processo de instituição de um gesto padronizado, típico da disciplinarização.

\section{A construção do gesto}

Em agosto de 1984, na edição de número 37, pela primeira vez foi publicada no Jornal uma fotografia focalizando um grupo de trabalhadores rurais carregando seus instrumentos de trabalho (Figura 1). Eles estão no campo (o fundo foi enquadrado de modo que a paisagem rural seja preponderante na composição) e o que os caracterizam como trabalhadores rurais são, justamente, seus instrumentos de trabalho: as enxadas. Todos estão carregando sua respectiva enxada sobre o ombro, numa nítida encenação para a câmera. 


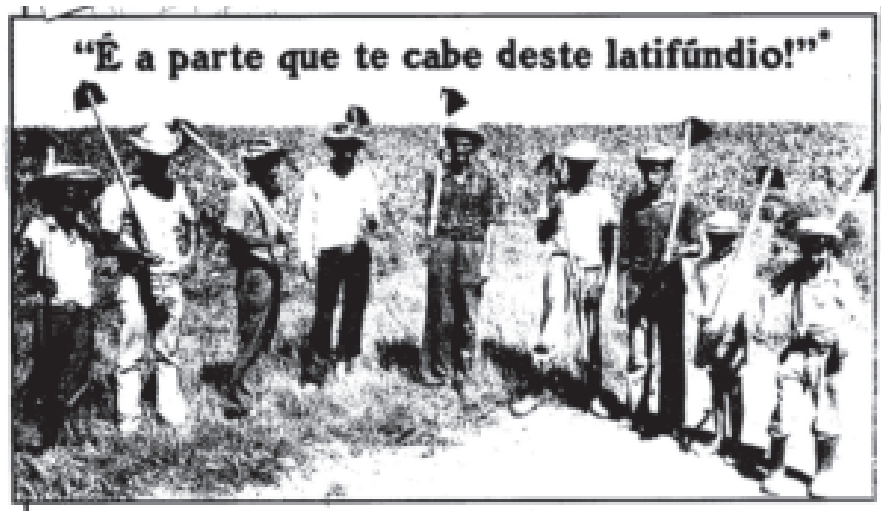

Figura 1 - Página do Jornal dos Trabalhadores Sem Terra Fotografia: Autoria não informada no jornal

Fonte: Jornal dos Trabalhadores Sem Terra /n. 37. Porto Alegre, ago. 1984

O discurso visual presente nesta imagem está de acordo com a forma tradicional pela qual o trabalhador rural é retratado na sociedade. $\mathrm{O}$ homem rural foi concebido, tanto por intelectuais quanto por artistas, através da produção de tipos. Um exemplo dessa forma de compreensão encontra-se em O povo brasileiro, de Darcy Ribeiro, em que ele caracteriza vários tipos de acordo com a localização geográfica, a formação étnica e a forma de produção e sobrevivência, como o caipira, o sertanejo, o caboclo e o gaúcho do pastoreio. $\mathrm{Na}$ arte, esses tipos são produzidos por pintores que os representam, na grande maioria das vezes, destacando exatamente esses três elementos: o espaço geográfico (caracterizando o fundo da tela de acordo com a paisagem rural de cada região do Brasil), a etnia (caracterizando o tipo físico do personagem e retratando-o no primeiro plano da tela, de modo que o observador possa identificar facilmente tais características) e a sua ocupação (retratando o personagem com seus instrumentos de trabalho mesmo quando não estão trabalhando). Dentre essas imagens, as mais notórias são os quadros do artista Almeida Júnior, como as telas Caipira Picando Fumo, Amolação Interrompida e Caipiras Negaceando. 


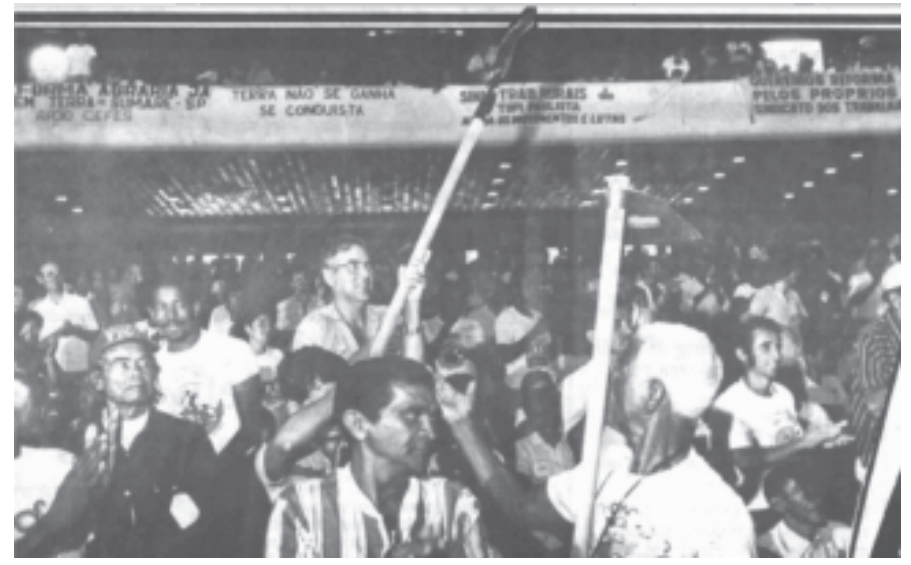

Figura 2 - Página do Jornal dos Trabalhadores Sem Terra Fotografia: Autoria não informada no jornal

Fonte: Jornal dos Trabalhadores Sem Terra /n. 42. Porto Alegre, fev. 1985

Se a visibilidade que cabia aos trabalhadores rurais remetia-os ao seu lugar no campo e a sua função de trabalhador, os sem-terra passam a instituir uma visibilidade que escapa desse lugar e dessa função. Essa ruptura pode ser observada na fotografia da capa da edição número 42, de fevereiro de 1985 (Figura 2). A imagem, feita no $1^{\circ}$ Congresso Nacional dos Sem Terra, realizado em Curitiba (PR), focaliza dois participantes erguendo enxadas em pleno auditório. O deslocamento da ferramenta de trabalho rural para o espaço da cidade e o ato de erguê-las como bandeiras em frente à câmera torna-as um símbolo não do lugar e da função do trabalhador rural, mas um símbolo da luta pela terra.

Ambas as fotografias (Figuras 1 e 2), tal como grande parte das imagens publicadas ao longo de suas edições, não são acompanhadas da identificação de sua autoria. Longe de ser uma questão de desleixo por parte da equipe do Jornal, tal fato pode ser entendido como a nãovalorização da individualidade autoral. Pode-se compreender isso como resultado da concepção de que a imagem e o texto, enfim, do saber dentro do Movimento, é coletivo. Há uma tentativa de construção de uma percepção do MST como uma entidade homogênea, na qual havia um discurso e uma imagem própria do todo. Assim, a questão da autoria, mesmo dando os devidos créditos nas legendas (sempre que possível) ao 
autor de cada fotografia, não será trabalhada. Isso porque se busca analisar um discurso imagético instituído no interior do Movimento, não advindo contribuições ou visões pessoais de certos fotógrafos.

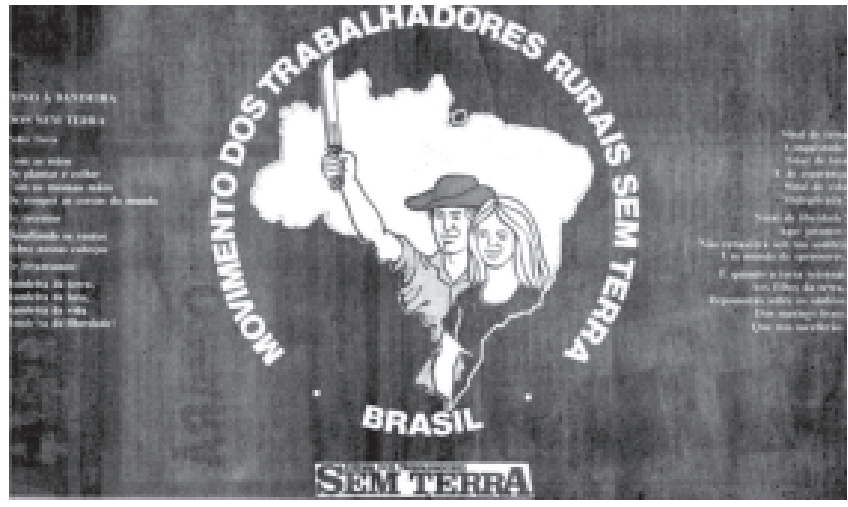

Figura 3 - Página do Jornal dos Trabalhadores Sem Terra Ilustração: Autoria não informada no jornal

Fonte: Jornal dos Trabalhadores Sem Terra/ n. 60. São Paulo, fev./mar. 1987

O símbolo do MST, estampado em suas bandeiras, camisas e bonés, é um casal dentro do contorno das fronteiras do Brasil. Esse símbolo apareceu pela primeira vez na edição de número 60 , de fevereiro e março de 1987 (Figura 3). A partir de então, foi cada vez mais difundido pelos mais diferentes meios. O símbolo é formado por um conjunto de elementos visuais que, relacionados entre si, geram um discurso imagético e sintético acerca das principais características pelas quais o Movimento julga importante ser reconhecido. Um dos elementos mais significativos nesse símbolo é o homem com seu braço direito completamente erguido e segurando um facão, remetendo à ideia de luta.

A imagem de uma multidão com todos os indivíduos erguendo um de seus braços apareceu pela primeira vez na edição de número 62, de maio de 1987 (Figura 4). Contudo, não se tratava de um grupo de semterra, mas de um momento da campanha das "Diretas Já". Em todo o espaço inferior da imagem, está a multidão de braço erguido. No espaço superior da imagem, está destacada uma parte da Câmara de Deputados Federais. Desse modo, o fotógrafo atingiu seu objetivo de enquadrar a 
manifestação de tal modo que a composição mostrasse a localização da manifestação e o grande número de manifestantes, além de construir a impressão de uma sintonia de todos no esforço de conseguir o objetivo em comum.

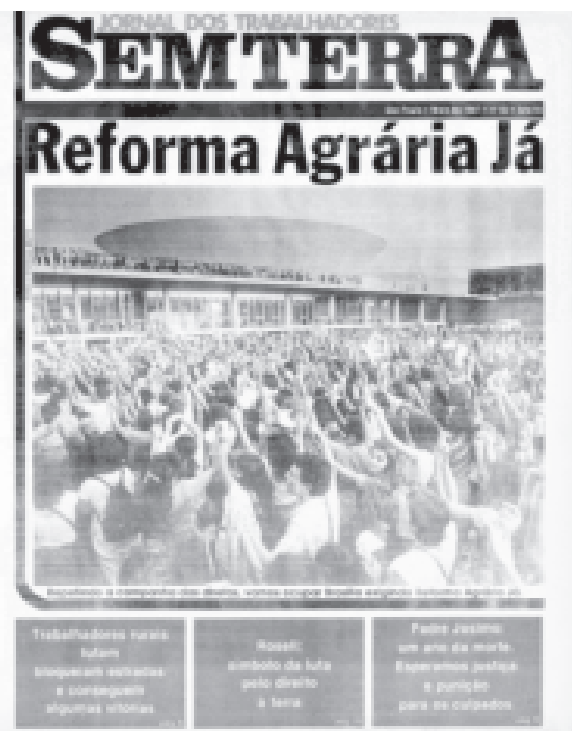

Figura 4 - Página do Jornal dos Trabalhadores Sem Terra

Legenda: "Repetindo a campanha das diretas, vamos ocupar Brasília exigindo Reforma Agrária Já "'

Fotografia: Cynthia Britto

Fonte: Jornal dos Trabalhadores Sem Terra/n. 62. São Paulo, mai. 1987

Investigando a relação da imagem com o Jornal, é possível levantar algumas questões. "Diretas Já" foi um movimento de grande registro audiovisual da história brasileira recente, com fotografias de enormes manifestações. Em várias imagens aéreas aparece uma multidão formada por indivíduos não alinhados, erguendo diferentes bandeiras. Há ainda as fotografias que registraram artistas e políticos na campanha, principalmente nos comícios. E há ainda várias imagens que registraram as seções da Assembléia Constituinte. Dentre todo esse conjunto de imagens feitas e disponíveis sobre as "Diretas Já", por que o Jornal selecionou justamente 
essa para estampar sua capa sobre a luta pela volta das eleições diretas no Brasil?

Tal fotografia contém um discurso imagético que está de acordo com o que dentro do MST passou a ser considerado o modo correto de aparecer coletivamente. $O$ texto reforça explicitamente essa mensagem ao vincular a foto à legenda: "Repetindo a campanha das diretas, vamos ocupar Brasília exigindo Reforma Agrária Já!’”. Nesse momento, o MST estava preparando uma caravana em direção a Brasília para realizar manifestações e reivindicar a reforma agrária. Mas essas manifestações deveriam ter uma determinada visibilidade e passar à sociedade certa imagem dos sem-terra - justamente uma imagem semelhante produzida naquela fotografia das "Diretas Já". A partir desta edição, passou a ser recorrente a publicação de fotografias de trabalhadores rurais sem-terra erguendo seus braços em conjunto, com o intuito de instaurar um determinado padrão de imagem dos sem-terra.

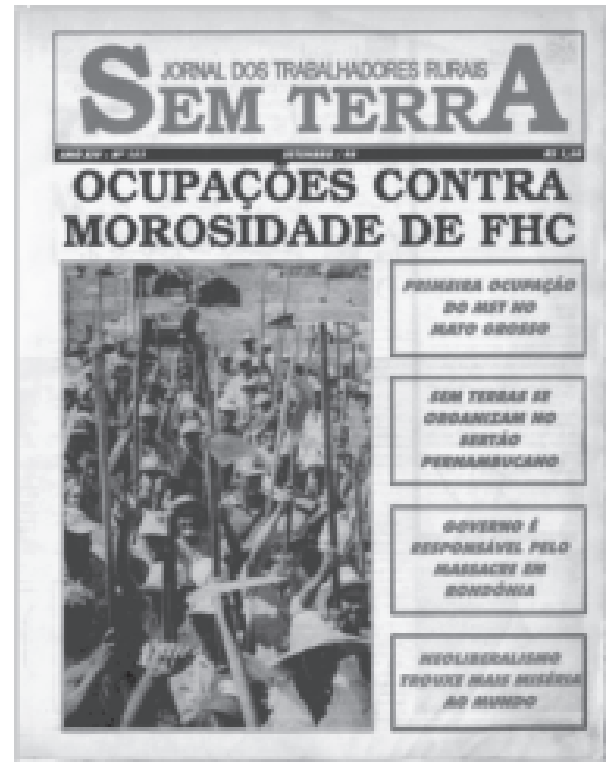

Figura 5 - Página do Jornal dos Trabalhadores Rurais Sem Terra Fotografia: Autor desconhecido

Fonte: Jornal dos Trabalhadores Rurais Sem Terra/ n. 151. São Paulo, set. 1995 
$\mathrm{Na}$ capa da edição número 151, de setembro de 1995, foi publicada a fotografia de um grupo de sem-terra erguendo o braço. $\mathrm{O}$ título "Ocupações contra a morosidade de FHC", institui um elemento essencial na concepção de luta: um inimigo a combater (Figura 5). No caso, a política agrária do governo, considerada pelo Jornal excessivamente vagarosa. Na imagem, vinculada na capa com tal título, o gesto de erguer as enxadas torna-se uma cena da luta pela aceleração da reforma agrária.

Investigar como um grupo criou algo aparentemente tão pequeno quanto um símbolo gestual contribui para analisar um processo histórico maior. A mecanização e a homogeneização dos gestos do corpo no coletivo são fundamentais no controle disciplinar dos indivíduos.

O controle disciplinar não consiste simplesmente em ensinar ou impor uma série de gestos definidos; impõe a melhor relação entre um gesto e a atitude global do corpo, que é a sua condição de eficácia e de rapidez. No bom emprego do corpo, que permite um bom emprego do tempo, nada deve ficar ocioso ou inútil: tudo deve ser chamado a formar o suporte do ato requerido. Um corpo bem disciplinado forma o contexto de realização num mínimo gesto. [...] O corpo disciplinado é a base de um gesto eficiente. (FOUCAULT, 1987, p.129).

A eficiência do gesto está na sua simplicidade, que facilita a obtenção do um coletivo sincronizado, nos seus múltiplos significados, em especial o de força e combatividade, e no efeito visual que gera, causando impacto no observador. Contudo, por mais que seja um gesto simples e eficiente, ele só é possível com corpos preparados para realizá-lo ao ouvir a voz de comando, seja na frente da câmara, tal como nas "Diretas Já", seja na frente da câmera, tal como nas capas do Jornal. 


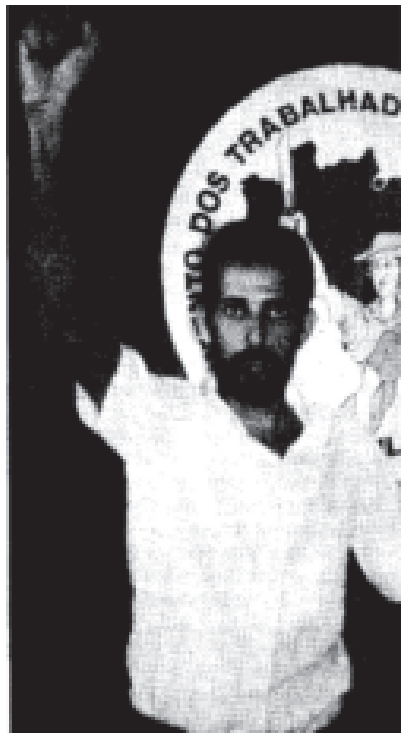

Figura 6 - José Rainha, membro da direção nacional do MST

Fotografia: Autor desconhecido

Fonte: Jornal dos Trabalhadores Rurais Sem Terra/n. 95. São Paulo, jul./ago. 1990

Na edição de julho/agosto de 1990, há a fotografia de uma pessoa com o braço erguido e a mão fechada (Figura 6). A identificação da pessoa se deve ao fato de ser um membro da direção nacional do Movimento, José Rainha. Nessa imagem, fica mais explícita a relação da fabricação do gesto com o estabelecimento da hierarquização no MST. Tal pessoa é individualizada por ser líder. O líder serve de modelo aos qualificados como base, sendo que suas palavras, seus atos e seus gestos deveriam ser supostamente reproduzidos pelos demais membros do Movimento.

Os sem-terra, dentro do MST, são focalizados cada vez menos individualmente ou em pequenos grupos, e cada vez mais em grandes grupos e até mesmo em multidões, homogeneizados pela fabricação do mesmo gesto. Nesse discurso imagético, não importa as características físicas dos sem-terra, mas sim a expressão numérica do Movimento, como na figura 5. A exceção se constitui nas fotografias de líderes, destacados individualmente, como na figura 6. Assim, o discurso imagético vincula-se 
a uma técnica de disciplina e hierarquização, que divide e padroniza indivíduos.

Na composição das fotografias aqui analisadas, é nítido um aspecto de teatralidade da fabricação das imagens. Acâmera não apenas registra o que está acontecendo, ela é um agente que fabrica e ordena o acontecimento. Na frente da câmera, os indivíduos tornam-se atores com um papel a desempenhar. Suas expressões corporais são pensadas de acordo com uma dramaticidade e o local é enquadrado como um cenário.

A fotografia é, como já vimos reiteradas vezes, o resultado de um processo de criação/reconstrução técnico, cultural e estético elaborado pelo fotógrafo. A imagem de qualquer objeto ou situação documentada pode ser dramatizada ou estetizada, de acordo com a ênfase pretendida pelo fotógrafo em função da finalidade ou aplicação a que se destina. (KOSSOY, 2002, p.52).

Na imagem da capa da edição número 151, é explícita a montagem teatral da fotografia (Figura 5). Os lavradores foram dispostos em um grupo coeso e, ao clique na câmera, produziram o gesto desejado. Assim, a imagem é resultado de uma encenação entre fotógrafo e fotografados, na fabricação da imagem desejada de acordo com valores estéticos de ambos e de acordo com a finalidade social da imagem em questão. $\mathrm{O}$ mesmo processo acontece na imagem de José Rainha. A liderança se posiciona na frente de uma bandeira do MST e, para ser fotografado, ergue seu braço com o punho cerrado (Figura 6). A bandeira se torna o pano de fundo da cena, e Rainha, o seu protagonista. $\mathrm{O}$ ato de erguer o braço se torna uma dramatização, uma encenação para ser registrada pela lente e, posteriormente, vista pelo público formado pelos leitores do Jornal.

Na instituição de um gesto padronizado, em especial no caso do braço erguido segurando uma foice, também deve ser analisada a relação entre o corpo e o objeto, tal como Foucault aponta em suas considerações: 
A disciplina define cada uma das relações que o corpo deve manter com o objeto que manipula. Ela estabelece cuidadosa engrenagem entre um e outro. [...] Sobre toda a superfície de contato entre o corpo e o objeto que o manipula, o poder vem se introduzir, amarraos um ao outro. Constitui um complexo corpo-arma, corpoinstrumento, corpo-máquina. Estamos inteiramente longe daquelas formas de sujeição que só pediam ao corpo sinais ou produtos, formas de expressão ou o resultado de um trabalho. A regulamentação imposta pelo poder é ao mesmo tempo a lei de construção da operação. E assim aparece esse caráter do poder disciplinar: tem uma função menos de retirada do que de síntese, menos de extorsão do produto do que de laço coercitivo com o aparelho de produção. (FOUCAULT, 1987, p.130).

Nessa fotografia de capa da edição de número 121, o enquadramento da imagem é ainda mais explícito ao destacar o gesto, quais instrumentos são usados e como esse gesto deve ser feito (Figura 7), definindo exatamente as relações que o corpo deve manter com instrumento durante a operação de erguê-lo.

No meio rural brasileiro, marcado por conflitos fundiários, os sem-terra erguem a foice, o machado e o facão como quem ergue suas armas de luta. Através do processo de disciplinarização, os semterra são amarrados a determinado objeto e certo modo de manipulálo que ligam seus corpos ao corpo do Movimento. Neste caso, de acordo com o discurso visual da capa do Jornal (Figura 7), ao manusear a foice ou facão, o corpo dos sem-terra deve estar com o braço totalmente erguido e segurar a ferramenta com toda a palma da mão no início do cabo. Erguendo todo o braço e ainda segurando a ferramenta no início do cabo, os sem-terra potencializam o gesto, fabricando uma imagem mais impactante.

Além do aspecto teatral, as fotografias também contêm um aspecto pedagógico. Analisando a da edição 121 é possível perceber o caráter instrutivo de tal imagem (Figura 7). Uma imagem é mais eficiente do que se fosse escrito e distribuído um manual de "como erguer o seu facão". Essa eficiência está justamente no fato de a imagem fotográfica ser vista no senso comum como uma apreensão da 
realidade, dissimulando a sua intenção. A fabricação, a seleção e a circulação da imagem correta têm sua maior eficiência devido a sua difícil percepção como um instrumento instrutivo.A imagem é corretiva sem ser coercitiva, divulgando a conduta correta como se fosse resultado da espontaneidade dos indivíduos.

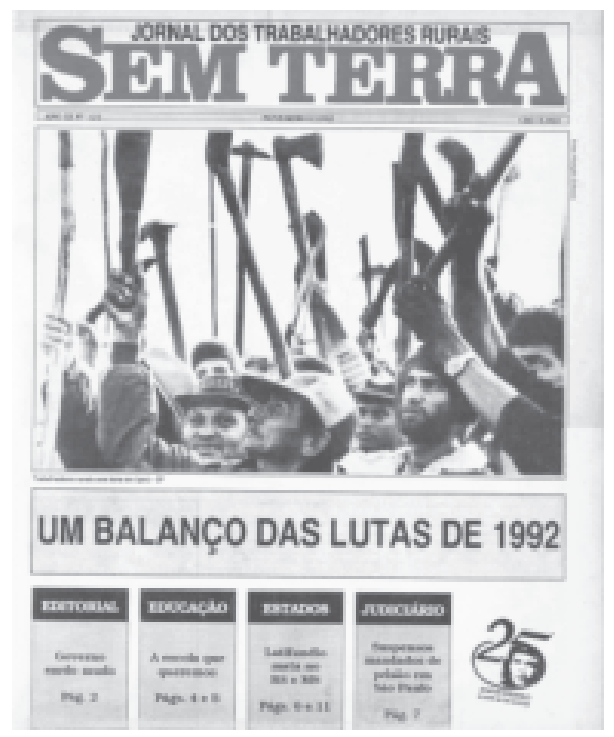

Figura 7 - Capa do Jornal dos Trabalhadores Rurais Sem Terra Legenda: "Trabalhadores rurais sem terra em Iperó - SP" Fotografia: Ramplis Zeitone

Fonte: Jornal dos Trabalhadores Rurais Sem Terra/n. 121. São Paulo, nov. 1992

O braço erguido já era um gesto relacionado a manifestações de protesto. Como visto, os manifestantes da campanha pelas eleições diretas erguiam seus braços como símbolo de protesto contra a ditadura militar. No entanto, o MST incorporou tal gesto com um acréscimo: o instrumento. O gesto de erguer o braço segurando um facão, tal como na bandeira do MST e exibido nas imagens dos semterra, é resultado do encontro de duas historicidades visuais: a de mostrar pessoas erguendo o braço com a mão cerrada como símbolo de protesto e a de retratar o homem do campo com seus instrumentos de trabalho. 
Outra imagem que possibilita analisar a fabricação do gesto é a da capa da edição número 85, de julho de 1989 (Figura 8). Na fotografia, em primeiro plano está uma mulher segurando uma enxada apoiada no ombro. No plano intermediário, está um homem sentado segurando uma foice. E, no plano de fundo, está destacada a bandeira do MST.

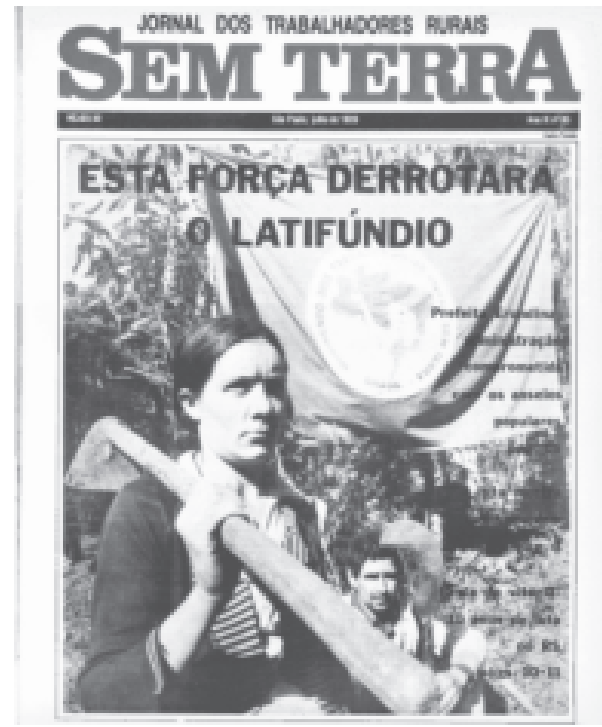

Figura 8 - Capa do Jornal dos Trabalhadores Rurais Sem Terra Fotografia: Autor desconhecido

Fonte: Jornal dos Trabalhadores Rurais Sem Terra/ n. 85. São Paulo, jul. 1989

Tal imagem causou tanto efeito que, além de ser publicada na capa, apareceu em outras duas edições do Jornal. Contudo, não foi reproduzida a fotografia, mas desenhos feitos a partir dela. Na primeira ilustração, publicada na edição 90, de dezembro de 1989, o homem é desenhado semelhante ao que está na imagem, mas num plano imediatamente atrás da mulher (Figura 9). Assim, continua sendo destacada a presença da mulher na imagem, mas é corrigido o tamanho da diferença de destaque entre ambos. Já no segundo desenho, publicado na edição 91, de janeiro e fevereiro de 1990, a presença do homem na imagem está equivalente à da mulher (Figura 10). Finalmente o homem e a mulher estão no mesmo 
plano, com o mesmo tamanho, a mesma expressão corporal, olhando na mesma direção, e com o símbolo do MST sobre eles. Assim, é fabricado e divulgado um discurso imagético que prega a equivalência de ambos os sexos no Movimento.

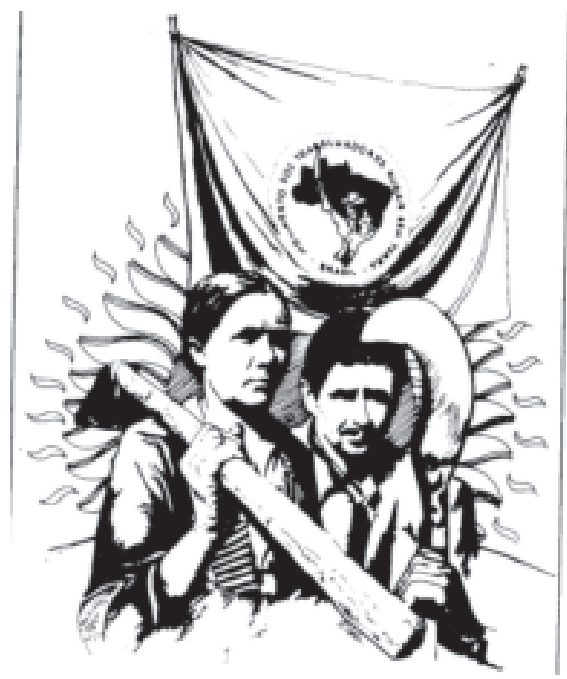

Figura 9 - Imagem publicada no Jornal dos Trabalhadores Rurais Sem Terra Ilustração: Autoria não informada no jornal

Fonte: Jornal dos Trabalhadores Rurais Sem Terra/ n. 90. São Paulo, dez. 1989

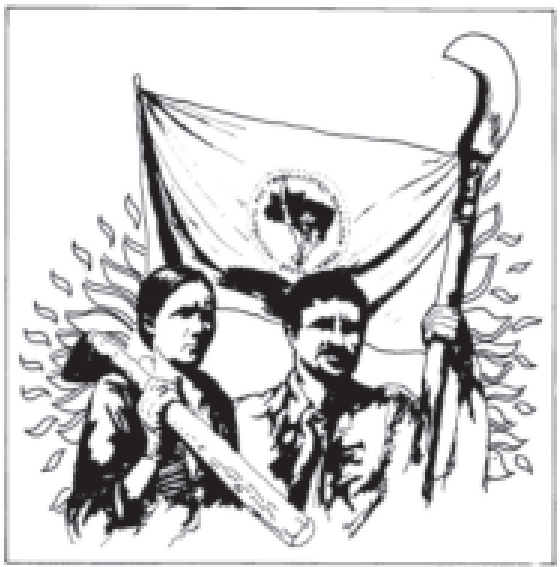

Figura 10 - Imagem publicada no Jornal dos Trabalhadores Rurais Sem Terra Ilustração: Autoria não informada no jornal

Fonte: Jornal dos Trabalhadores Rurais Sem Terra/ n. 91. São Paulo, jan./fev. 1990 
No entanto, se, nessa série de imagens, o que pode mais chamar atenção à primeira vista é a correção da relação entre o homem e a mulher, deve-se também analisar a correção efetuada no gesto de segurar a foice. Cabe aqui utilizar o termo "correção" levando em consideração o que dentro do MST é considerado "erro". Nesse caso, erro é aquilo que não está em conformidade com o discurso oficial, controlado por sua direção.

$\mathrm{Na}$ fotografia, o homem sentado no chão segura a foice com a ponta dos dedos e o braço na altura do peito. A ponta da foice aparece um pouco acima de sua cabeça. Já na última imagem, o homem é desenhado em pé, totalmente ereto, erguendo o braço e segurando a foice pelo cabo. Nessa série de três imagens, a correção do gesto revela a deliberação de instituir tal gesto como símbolo dos sem-terra. Longe de ser uma marca natural dos sem-terra e do MST, esse gesto foi fabricado dentro de um processo de disciplinarização, no qual passam a ser modeladas posturas corporais e condutas. Na imagem ideal, o sem-terra, com tal gesto, é constituído em um complexo corpoinstrumento que inscreve no corpo do sem-terra a marca do Movimento.

\section{Considerações finais}

Pode-se concluir que, no interior do MST, a conduta e a visibilidade dos sem-terra foram modeladas dentro de uma lógica disciplinar. Essa normatização pode ser analisada em sua positividade, não como apenas um aparato coercitivo ou repressor, pois seu objetivo era produzir um grupo socialmente mobilizado para o litígio em torno da terra e da própria ordem social. O registro e a divulgação das imagens dos sem-terra no Jornal do Movimento não tiveram a função de apenas evidenciar um modo de ser e de se comportar que seria supostamente próprio dos sem-terra. A imagem é fabricada num 
processo no qual se seleciona o que deve e o que não deve ser visto, focalizando aquilo que se interessa tornar visível e repetível, instaurando, assim, a padronização de modos de condutas. $\mathrm{Na}$ sociedade contemporânea, marcada tão fortemente pelo visual, é imprescindível analisar o caráter normatizador que as imagens comportam.

\section{Referências}

\section{CAUME, David José. O MST e os assentamentos de reforma} agrária: a construção de espaços sociais modelares. Goiânia: Editora da Universidade Federal de Goiás, 2006.

FOUCAULT, Michel. Microfísica do poder. Tradução de Roberto Machado. Rio de Janeiro: Graal, 1979.

.Vigiar e punir. Tradução de Raquel Ramalhete. Petrópolis: Vozes, 1987.

KOSSOY, Boris. Realidades e ficções na trama fotográfica. São Paulo: Ateliê Editorial, 2002.

RIBEIRO, Darcy. O povo brasileiro: a formação e o sentido do Brasil. São Paulo: Companhia das Letras, 1995

STÉDILE, João Pedro; FERNANDES, Bernardo Mançano. Brava gente: a trajetória do MST e luta pela terra no Brasil. São Paulo: Fundação Perseu Abramo, 1999. 